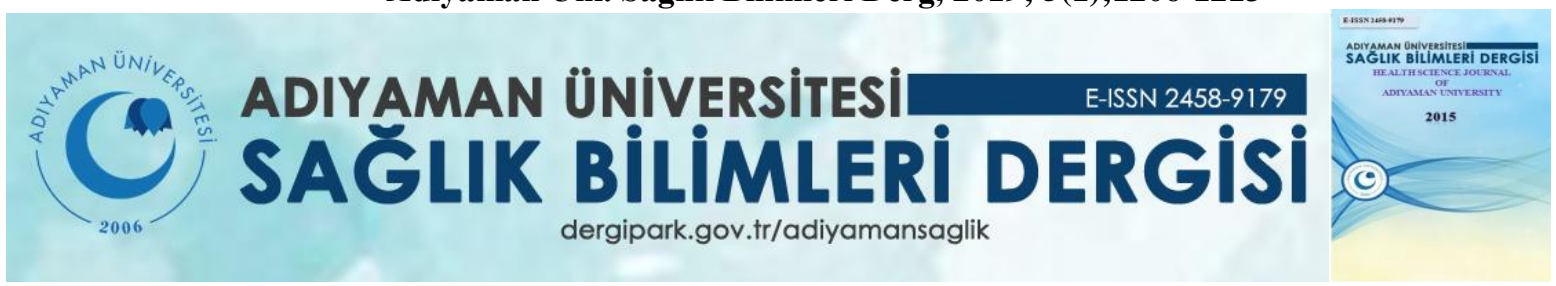

\title{
Araştırma/Research \\ Preterm doğum riski olan çoğul gebelerde akciğer maturasyonu için kortikosteroid kullanımı; Perinatal sonuçlar
}

\author{
Mehmet BÜLBÜL ${ }^{1}$, Esra BOYAR ${ }^{1}$, İpek ÇAKILKAYA ${ }^{1}$, Selahattin AKAR $^{2}$ ve Berna DİLBAZ ${ }^{3}$
}

${ }^{1}$ Adıyaman Üniversitesi Tıp Fakültesi, Kadın Hastalıkları ve Doğum AD, Adıyaman, Türkiye.

${ }^{2}$ Adıyaman Üniversitesi Tıp Fakültesi, Çocuk Sağlığı ve Hastalıkları AD, Adıyaman, Türkiye

${ }^{3}$ Sağlık Bilimleri Üniversitesi, Kadın Hastalıkları ve Doğum AD, Etlik Zübeyde Hanım Sağlık Uygulama Araştırma Hastanesi, Ankara.

öz.

Amaç: Erken doğmuş bebeklerde respiratuvar distres sendromunun (RDS) önlenmesinde antenatal kortikosteroid (AKS) tedavisi yaygın bir şekilde kullanılmasına rağmen, bu tedavinin çoğul gebeliklerdeki sonuçları halen tartışmalıdır. Bu çalışmanın amacı, erken doğum riski taşıyan çoğul gebeliklerde AKS'in etkisini araştırmaktır.

Yöntem: İki yıllık bir dönemde bir Üniversite Hastanesinde çoğul gebelik ve erken doğumu riski ile hospitalize edilerek doğum yapan 68 kadının tıbbi kayıtları incelendi. Çalışmaya alınan kadınların 67'si ikiz gebelik, bir tanesi ise üçüz gebelikti. Demografik özellikler, obstetrik öykü, gebelik yaşı, maternal komorbidite varlığı, doğum şekli, maternal ve fetal sonuçlar kaydedilerek incelendi.

Bulgular: Olguların yaş ortalaması $31,9 \pm 5,7$ yıldı. Hastaneye yatırıldıklarında ortalama gebelik haftası $33.1 \pm 2.5$ haftaydı. Hastaların \%48,5'i spontan, \%26,5'i kontrollü ovaryan stimülasyon ve intrauterin inseminasyon ve $\% 25$ 'i in vitro fertilizasyon ve embriyo transferi yöntemiyle gebe kalmışt. Altmış sekiz hastanın 45 'inde $(\% 66,2)$ tek doz, 23'ünde (\% 33.8) multidoz kortikosteroid uygulandı. Kortikosteroid ile doğum arasındaki ortalama süre $81 \pm 276$ saat idi. Postpartum dönemde bir hastada fasiyal paralizi ve bir hastada da cerrahi alan enfeksiyonu gelişti. Doğan 137 bebeğin \%51,1'inde yoğun bakım gereksinimi olmaz iken, \%48.9'u yenidoğanın geçici takipnesi, RDS, sarılık nedeni ile yenidoğan yoğun bakım (YDYB) ünitesine alındı. Üç yenidoğan postpartum dönemde kaybedildi (650, 750 ve 875 gr).

Sonuç: Çoğul gebeliklerin yaklaşı \% 50'sinde görülen preterm doğum yenidoğan mortalite/morbiditesi için önemli risk oluşturmaktadır. Çoğul gebelerde preterm doğum bağlı gelişecek RDS'nin önlenmesi ve YDYB ihtiyacının azaltılması için AKS kullanımı önemlidir. Preterm doğum ile komplike olan çoğul gebeliklerde RDS gelişimi sağ kalımı etkileyen en önemli faktördür. RDS önlenmesinde AKS kullanımı önemlidir.

Anahtar kelimeler: Antenatal Kortikosteroid; Repratuvar Distres Sendromu; Çoğul Gebelikler; Preterm Doğum

\begin{tabular}{l}
\hline Yazışmadan Sorumlu Yazar \\
\hline Mehmet Bülbül \\
Adıyaman Üniversitesi Tıp Fakültesi Kadın Hastalıkları ve \\
Doğum AD \\
Tel : (+90) 4162231690 \\
Email: mehmetbulbulmd@gmail.com
\end{tabular}

DOI:10.30569/adiyamansaglik. 490432

\begin{tabular}{ll}
\hline Geliş Tarihi: & $\mathbf{3 0 . 1 1 . 2 0 1 8}$ \\
\hline Kabul Tarihi: & $\mathbf{2 8 . 1 2 . 2 0 1 8}$ \\
\hline
\end{tabular}




\section{Use of corticosteroids for lung maturation in multiple pregnant at risk of preterm delivery; Perinatal outcomes.}

Objective: Although antenatal corticosteroid (ACS) treatment is widely used for prevention of respiratory distress syndrome (RDS) in preterm infants the results of this treatment is still controversial in multiple pregnancies. The aim of this study is to evaluate the effect of antenatal corticosteroid on the mother and the neonate in multiple pregnancies at risk of preterm birth.

Methods: Medical records of 68 women with twin or triplet pregnancies at risk of preterm birth who delivered at a University Hospital in two years period were analyzed. Sixty-seven of the women recruited had twin pregnancy while the remaining one had triplets. The demographic characteristics, obstetric history, gestational age, presence of maternal comorbidities, mode of delivery, maternal and fetal outcome were recorded.

Findings: The average age of the patients was $31.9 \pm 5.7$. The average week of pregnancy at admission to the hospital was $33.1 \pm 2.5$ weeks. $48.5 \%$ of the patients had spontaneous pregnancy while $26.5 \%$ got pregnant after controlled ovarian hyperstimulation and intrauterine insemination and $25 \%$ had in vitro fertilization and embryo transfer. Out of 68 patients $45(66.2 \%)$ received single dose, 23 had (33.8\%) multi doses of corticosteroids. The average time between corticosteroid administration and delivery was $81 \pm 276$ hours. One patient had facial paralysis and another one had surgical site infection during the postpartum period. Out of 137 babies delivered, $70(51.1 \%)$ were not admitted to the Neonatal Intensive Care Unit (NICU) while the indications for admission in the remaining $48.9 \%$ were RDS, icterus and transient tachypnea of the neonate. Three neonates did not survive $(650,750$ and 875 gr).

Conclusion: Preterm birth that is encountered in 50\% of the multiple pregnancies is a major risk factor for neonatal morbidity and mortality. In order to prevent RDS and decrease the need for admission to NICU it is important to administer ACS. In multiple pregnancies complicated with preterm delivery, development of RDS has the highest impact on survival. ACS use is important for prevention of RDS.

Keywords: Antenatal corticosteroid; Repratory Distress Syndrome; Multiple Pregnancy; Preterm Birth 


\section{Giriş}

Günümüzde birçok nedene bağlı olarak çoğul gebelik oranlarında artış mevcuttur (1). Bu artış tekil gebeliklerle kıyaslandığında başta preterm doğum olmak üzere maternal ve fetal problemlerde artışa sebep olmaktadır. Ayrıca çoğul gebeliklerde fetüs sayısı arttıkça preterm doğum oranı artmaktadır.

Preterm doğum neonatal mortalite ve morbiditenin en önemli nedenlerinden biridir. Preterm doğan bebeklerde yeni doğanın geçici takipnesi (TTN), respiratuar disstres sendromu (RDS), bronkopulmoner displazi, kistik periventriküler lökomalazi, sepsis, intraventriküler hemoraji, nekrotizan enterokolit, patent duktus arteriyozus, prematür retinopatisi ve serebral palsi gibi morbiditelerin görülme sıklığı $\operatorname{artmaktadır~(2).~}$

Preterm doğum riski taşıyan gebelerde yeni doğan sonuçlarını iyileştiren en önemli tedavilerden biri antenatal dönemde kortikosteroid (AKS) uygulanmasıdır (2). Erken doğma riski olan bebeklerde AKS tedavisi RDS ve diğer morbiditelerin önlenmesinde yaygın bir şekilde kullanılmaktadır. Bununla birlikte bu tedavinin çoğul gebeliklerdeki sonuçları halen tartışılmaktadır. Çünkü çoğul gebeliklerde AKS kullanımı ile ilgili çalışmalar halen sınırlıdır ve yeterince kanıt bulunmamaktadır (3-5).

Bu çalışmanın amacı, erken doğum riski taşıyan çoğul gebeliklerde antenatal kortikosteroidin anne ve yenidoğan sağlığına etkisini araştırmaktır.

\section{Gereç ve Yöntemler}

Çalışma Adıyaman Üniversitesi Tıp Fakültesi Biyomedikal Etik Kurulu onayından (Karar No: 2018/8-15) sonra Adıyaman Üniversitesi Tıp Fakültesi Hastanesi Riskli gebelik servisinde yapıldı. Doğum kayıtları 01.05.2016 - 01.05.2018 tarihleri arasını kapsayacak şekilde araştırıldı.

Kliniğimizde 34. gebelik haftasından küçük, erken doğum tehdidi ile yatırılan tüm hastalara 24 saat ara ile $12 \mathrm{mg}$ betametazon (Celestone Chronodose Ampul; Schering Plough Tibbi Ürünler Ticaret A.Ş.) intramuskuler bir kür olarak uygulanmaktadır. Hastaların doğumu daha kısa sürede gerçekleşecek olsa da ilk doz AKS mutlaka yapılmaktadır.

Preterm doğum ön tanısıyla AKS uygulanan ve doğumunu hastanemizde gerçekleştiren çoğul gebeler çalışmaya dahil edildi. Hastaların kayıtları hastane bilgi sisteminden ve bebek bilgileri 
yeni doğan kayıtları incelenerek kaydedildi. Çalışmaya dahil edilme kriterleri çoğul gebelik olması, AKS uygulanmış olması, hastane kayıtlarının tam olması ve hastanemizde doğumun gerçekleşmiş olması idi. Kortikosteroid uygulanmamış, preterm olmayan, kayıtları eksik olan, fetal konjenital anomalisi olan vakalar çalışma dışı bırakıldı.

Toplam 95 hastanın dosyasına ulaşıldı (Şekil 1) bu hastalardan çalışma kriterlerini karşılamayan 27 hasta çalışma dışı bırakıldı. Erken doğum risk altında olan ikiz veya üçüz gebeliği olan 68 kadın çalışmaya alındı. Bu kadınların 67'sinde ikiz gebelik, bir tanesinde ise üçüz gebelik vardı. Demografik özellikler, obstetrik öykü, gebelik yaşı, maternal komorbidite varlığı, doğum şekli, maternal ve fetal sonuçlar kaydedildi.

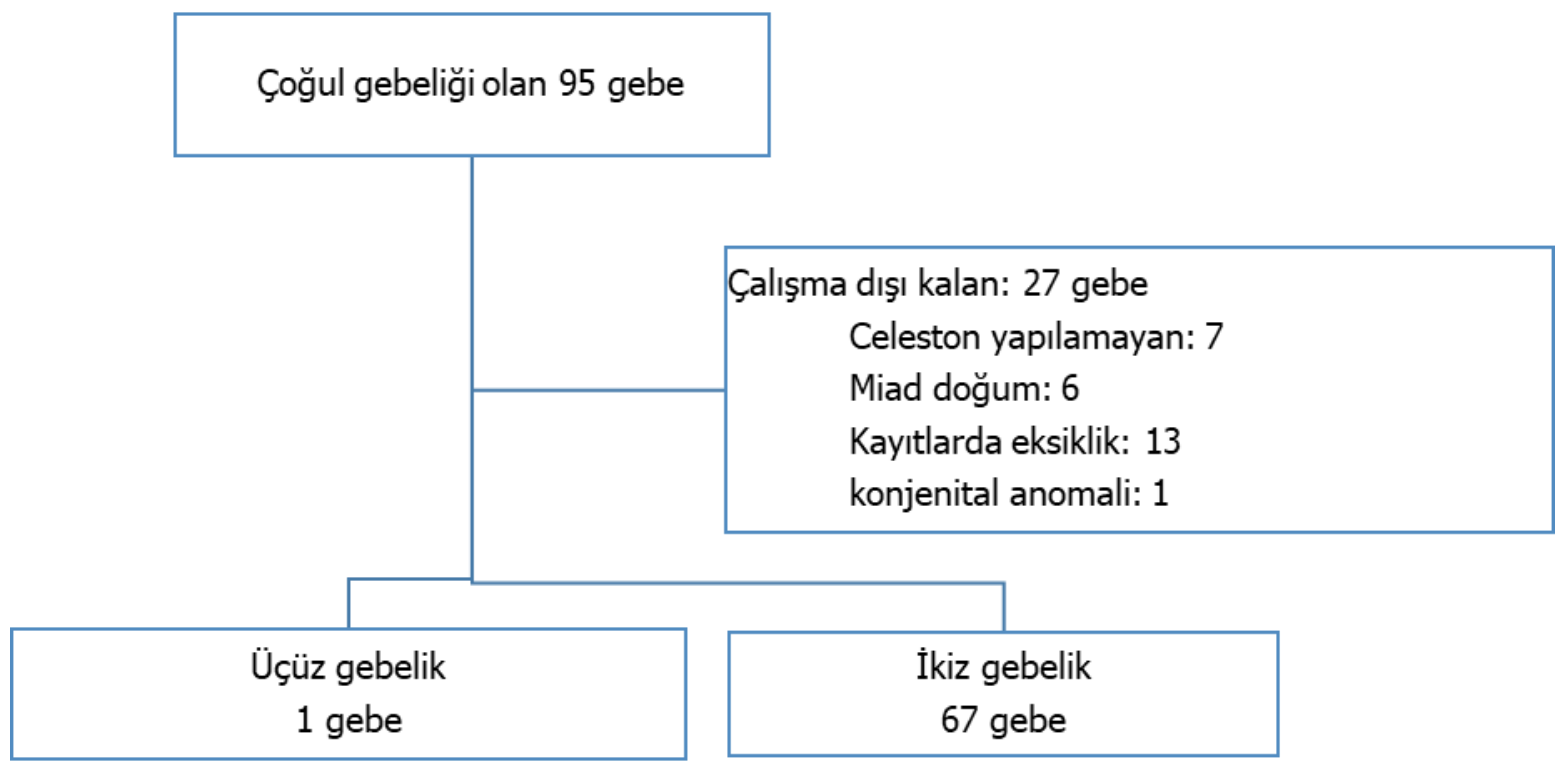

\section{Şekil 1: Hasta diagramı.}

İstatistiksel analizler için SPSS 23 (Statistical Package for the Social Sciences software version 15) kullanıld1. Bulgular ortalama \pm standart sapma ve minimum-maksimum olarak verilirken kategorik değişkenler sayı ve yüzde olarak verildi.

\section{Bulgular}

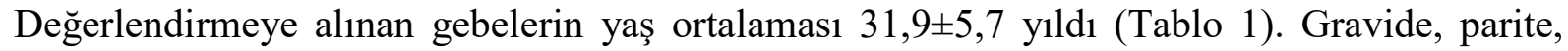
abortus ve canlı çocuk sayısı sırasıyla $2(\mathrm{R}=1-6), 1(\mathrm{R}=0-5), 0(\mathrm{R}=0-2), 1(\mathrm{R}=0-5)$ idi. Çoğul gebeliklerin \%48,5'i spontan olarak gelişmiş iken, \%26,5'i kontrollü ovaryan stimülasyon ve intrauterin inseminasyon ve \%25'i in vitro fertilizasyon ve embriyo transferi 
sonrası gebelikler idi. Altmış sekiz hastanın yedisinde (\% 10,3) gestasyonel diyabetes mellitus (GDM), 11 (\%16,2)'inde hipertansiyon, 1 (\%1,5)'inde hipotiroidi, 1 (\%1,5)'inde GDM+ITP (İmmün Trombositopenik Purpura) ve $2(2,9)$ 'sinde astım bronşiale vardı. Dört hastada (\% 5.9) başvuru anında idrar yolu enfeksiyonu vardı.

Tablo 1: Hastaların demografik verileri.

\begin{tabular}{|c|c|c|}
\hline & & $\mathrm{N}=68$ \\
\hline Anne Yaş1 (yıl) (Mean \pm SD) & & $31,9 \pm 5,7$ \\
\hline Gravide (median(min-max)) & & $2(1-6)$ \\
\hline Parite (median(min-max $)$ ) & & $1(0-5)$ \\
\hline Abortus (median(min-max)) & & $0(0-2)$ \\
\hline Yaşayan çocuk (median(min-max)) & & $1(0-5)$ \\
\hline \multirow{3}{*}{ Gebelik Şekli (n) (\%) } & Spontan & $33(48,5)$ \\
\hline & $\mathrm{COH}+\mathrm{IUI}$ & $18(26,5)$ \\
\hline & IVF+ET & $17(25,0)$ \\
\hline \multirow{6}{*}{ Sistemik Hastalık (n) (\%) } & Yok & $46(67,6)$ \\
\hline & GDM & $7(10,3)$ \\
\hline & HT & $11(16,2)$ \\
\hline & Hipotiroidi & $1(1,5)$ \\
\hline & GDM+ITP & $1(1,5)$ \\
\hline & Astım & $2(2,9)$ \\
\hline Üriner enfeksiyon (n) (\%) & & $4(5,9)$ \\
\hline
\end{tabular}

COH+IUI: Kontrollü ovaryan hiperstimulasyon ve inseminasyon, IVF+ET: In vitro fertilizasyon+Embriyo transferi, GDM: Gestasyonel Diyabet mellitus, HT: hipertansiyon, ITP: Immü̈n Trombositopenik Purpura

Hastaneye yatırıldıklarında ortalama gebelik haftaları 33,1 $\pm 2,5$ haftaydı (Tablo 2). Yattıklarındaki ortalama servikal açıklık 2,1 $\pm 1,4 \mathrm{~cm}$ ve ortalama servikal silinme $\% 34 \pm 22,2$ olarak saptandı. Tüm hastalara nifedipin ile tokolitik tedavi uygulandı. Hastalarda tokoliz süresinin yeterliliğine bağlı olarak 68 hastanın 45'i $(\% 66,2)$ tek doz, 23'ü (\% 33.8) iki doz

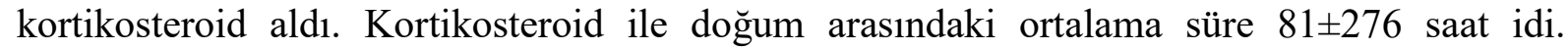
Gebeler yatıştan ortalama 17,8 $\pm 44,4$ saat sonra doğumlarını gerçekleştirdiler. Gebelerin 59’u ilk yatışında doğururken, 9'unda doğum daha sonra gerçekleşti. Çalışmaya dahil edilen tüm gebeler sezaryen ile doğurtuldu.

Bebeklerin ortalama kilosu 1997,4 $\pm 521,4$ gr olarak saptanırken bebeklerin 73 'ü $(\% 53,3)$ k1z, 64'ü $(\% 46,7)$ erkekti (Tablo 3). Bebeklerin 70 'inde $(\% 51,1)$ yoğun bakım ihtiyacı olmadı. Kirk bebek $(\% 29,2)$ TTN, 18 bebek $(\% 13,1)$ RDS ve $6(\% 4,4)$ bebek sarıl1k tanılarıyla YDYBÜ'ne yatırıld1. Yeni doğan bebeklerden ileri derecede prematüre olan $3(\% 2,2)$ bebek postpartum dönemde ex oldu (Doğum kilolar1: 650 gr, 750 gr ve 875 gr). Maternal 
komplikasyonlar değerlendirildiğinde postpartum bir hastada yüz felci ve bir hastada da cerrahi alan enfeksiyonu gelişti.

Tablo 2: Maternal bulgular.

\begin{tabular}{lcc} 
& $\mathrm{N}=68$ \\
\hline Gebelik Haftası (hafta) (Mean \pm SD) & $33,1 \pm 2,5$ \\
\hline Servikal dilatasyon (cm) (Mean \pm SD) & & $2,1 \pm 1,4$ \\
\hline Servikal effasman (\%) (Mean \pm SD) & 12 mg betametazon & $34,3 \pm 22,2$ \\
\hline Kortikosteroid uygulaması (n) (\%) & >24 mg betametazon & $23(66,2)$ \\
\hline Yatış ve doğum arasındaki zaman (saat) (Mean \pm SD) & & $23,8)$ \\
\hline AKS ve doğum arasındaki zaman (saat) (Mean \pm SD) & & $81,0 \pm 44,4$ \\
\hline EMR (n) $(\%)$ & & $8(11,8)$ \\
\hline Antibiyotik kullanımı (n) (\%) & $2(2,9)$ \\
\hline Maternal Komplikasyon (n) (\%) & Sezaryen & $2(2,9)$ \\
\hline Doğum şekli (n) (\%) & & $68(100)$ \\
\hline
\end{tabular}

EMR: erken membran rüptürü

Tablo 3: Fetal bulgular.

\begin{tabular}{|c|c|c|}
\hline & & $\mathrm{N}=137$ \\
\hline Bebek Doğum kilosu (gr) (Mean \pm SD) & & $1997,4 \pm 521,4$ \\
\hline \multirow{2}{*}{ APGAR skoru $(\mathrm{Mean} \pm \mathrm{SD})$} & 1.Dakika & $7,3 \pm 1,6$ \\
\hline & 5. Dakika & $8,6 \pm 1,5$ \\
\hline \multirow{2}{*}{ Bebek Cinsiyet (n) (\%) } & K1z & $73(53,3)$ \\
\hline & Erkek & $64(46,7)$ \\
\hline \multirow{5}{*}{ YDYBÜ yatış $(\mathrm{n})(\%)$} & Yok & $70(51,1)$ \\
\hline & TTN & $40(29,2)$ \\
\hline & RDS & $18(13,1)$ \\
\hline & Sarılık & $6(4,4)$ \\
\hline & Ex & $3(2,2)$ \\
\hline
\end{tabular}

YDYBÜ: Yenidoğan yoğun bakım ünitesi, RDS: Respiratuar distres sendromu, TTN: yenidoğanın geçici takipnesi.

\section{Tartışma}

AKS uygulaması, preterm doğum riski olan hastalar için neonatal sonuçları iyileştirmede çok önemli bir tedavi yöntemidir. Bu tedavi ile yenidoğanda RDS gibi birçok morbiditenin görülme riski azalır. Bu olumlu etki 23 haftalık gebeliğin başlangıcından itibaren mevcuttur. Son yapılan bazı çalışmalarda benzer etkiler geç preterm dönemde de gösterilmiştir (6). Bununla birlikte ikiz gebeliklerde KS kullanımı ile ilgili daha az çalışma mevcuttur. Çoğul gebelerdeki preterm doğum insidansının yüksek olması, tekil gebeliklere göre daha yüksek YDYB gereksinimine sebep olmaktadır. Bizim çalışmamızda da doğum yapan 137 bebekten 70'inde YDYBÜ ihtiyacı olmadı. 
Perinatal sonuçları iyileştirmek için, 24-31. haftalarda preterm doğum riski taşıyan ikiz gebeliği olan tüm annelerde AKS düşünülmelidir (7). $\mathrm{Bu}$ hastalarda önemli tartışma konularından biri de doğum gerçekleşmediğinde ek doz yapılıp yapılmayacağıdır. İlk doz AKS yapıldıktan sonra 1-2 saat içinde fetal koruyucu etki başlar. Fakat fetal mortalite, RDS ve ciddi nörolojik hasarlarda belirgin azalmanın olduğu dönem 2-7 gün arasıdır $(8,9)$. Yedi günden sonra etkisi azalmaya başladığı için bu hastalarda bir hafta sonra preterm riski devam ederse hatırlatma dozu uygulamak gerekmektedir (10). Bizim çalışmamızda da 9 hastada ilk yatışlarında AKS yapılmış olmasına rağmen doğumları sonraki yatışlarında gerçekleşti. Bu dokuz hastanın beşine doğum anında gebelik haftaları 34 haftadan büyük olduğu için hatırlatma dozu uygulanmadi.

İkinci kür AKS kullanımının neonatal sepsis oranını arttırmadığı gösterilse de (11) AKS proflaksisinde önemli olan bir konuda tekrarlayan dozlarda yapıldığında artan fetal ve maternal yan etkilerdir. Bundan dolayı erken term /geç preterm dönemde AKS proflaksisini önermeyen çalışmalar da mevcuttur (12). Bunun aksine 37 hafta üzerinde planlı sezaryen olgularında uygulandığında RDS ve YDYB ihtiyacı yaklaşık iki kat azalttı̆̆ını gösteren çalışmalarda mevcuttur $(13,14)$. Bizim çalışmamızda da hatırlatma dozu yapılan üç hastada (6 bebek) komplikasyon gelişmedi.

Sonuç olarak çoğul gebeliklerin yaklaşık \% 50'sinde görülen preterm doğum yenidoğan mortalite/morbiditesi için önemli risk oluşturmaktadır. Preterm doğum ile komplike olan çoğul gebeliklerde sağ kalımı etkileyen en önemli faktör şiddetli prematüritedir. Çalışmamızda da gösterildiği gibi çoğul gebeliklerde AKS proflaksisi fetal mortalite ve morbidite için hayati öneme sahiptir. Fakat hangi haftalarda hangi dozlarda ve gereklilik halinde ek doz ihtiyacını belirlemek için randomize kontrollü çalışmalara ihtiyaç vardır.

Çıkar Çatışması: $\mathrm{Bu}$ çalışma herhangi bir organizasyon tarafından finanse edilmemiştir. Tüm yazarlar finansal ve çıkar çatışmasının olmadığını kabul ve beyan eder. 


\section{Kaynaklar}

1. Kulkarni AD, Jamieson DJ, Jones Jr HW, Kissin DM, Gallo MF, Macaluso M, et al. Fertility treatments and multiple births in the United States. N Engl J Med 2013;369(23):2218-25.

2. Ward RM, Beachy JC. Neonatal complications following preterm birth. BJOG 2003;110:8-16.

3. Roberts D, Dalziel S. Antenatal corticosteroids for accelerating fetal lung maturation for women at risk of preterm birth. Cochrane Database Syst Rev 2006;3, CD004454.

4. Gyamfi C, Mele L, Wapner RJ, Spong CY, Peaceman A, Sorokin Y, et al. The effect of plurality and obesity on betamethasone concentrations in women at risk for preterm delivery. Am J Obstet Gynecol 2010;203(3):219.e1-5.

5. Blickstein I, Shinwell ES, Lusky A, Reichman B, in collaboration with the Israel Neonatal Network. Plurality-dependent risk of respiratory distress syndrome among very-low-birth-weight infants and antepartum corticosteroid treatment. Am J Obstet Gynecol 2005;192(2):360-4.

6. Booker WA, Gyamfi-Bannerman C. Antenatal Corticosteroids: Who Should We Be Treating? Clin Perinatol. 2018;45(2):181-198. doi: 10.1016/j.clp.2018.01.002.

7. Riskin-Mashiah S, Reichman B, Bader D, Kugelman A, Boyko V, Lerner-Geva L, Riskin A. Populationbased study on antenatal corticosteroid treatment in preterm small for gestational age and non-small for gestational age twin infants. J Matern Fetal Neonatal Med. 2018;31(5):553-559. doi: $10.1080 / 14767058.2017 .1292242$

8. Melamed N, Shah J, Yoon EW, Pelausa E, Lee SK, Shah PS, Murphy KE; Canadian Neonatal Network Investigators. The role of antenatal corticosteroids in twin pregnancies complicated by preterm birth. Am J Obstet Gynecol. 2016;215(4):482.e1-9.

9. Vaz A, Malheiro MF, Severo M, Rodrigues T, Guimarães H, Montenegro N. Effect of antenatal corticosteroids on morbidity and mortality of preterm singletons and twins. J Matern Fetal Neonatal Med. 2018; 31(6):754-760. doi: 10.1080/14767058.2017.1297408. Epub 2017 Mar 9.

10. Fillion A, Boutin A, Gareau-Léonard A, Labine L, Gasse C, Gaudreau C, Demers S, Bujold E. Use of Antenatal Corticosteroid Therapy: A Descriptive Study of Clinical Practice Trends. J Obstet Gynaecol Can. 2018 23. pii: S1701-2163(18)30523-1.

11. Gyamfi-Bannerman C, Son M. Preterm Premature Rupture of Membranes and the Rate of Neonatal Sepsis After Two Courses of Antenatal Corticosteroids. Obstet Gynecol. 2014;124(5):999-1003.

12. Haviv HR, Said J, Mol BW. The place of antenatal corticosteroids in late preterm and early term births Semin Fetal Neonatal Med. 2018 4. pii: S1744-165X(18)30112-4.

13. Sotiriadis A, Makrydimas G, Papatheodorou S, Ioannidis JP, McGoldrick E. Corticosteroids for preventing neonatal respiratory morbidity after elective caesarean section at term. Cochrane Database Syst Rev. 2018 Aug 3;8:CD006614.

14. Salem SY, Kibel M, Asztalos E, Zaltz A, Barrett J, Melamed N. Neonatal Outcomes of Low-Risk, LatePreterm Twins Compared With Late-Preterm Singletons. Obstet Gynecol. 2017;130(3):582-590. doi: 10.1097/AOG. 0000000000002187. 